\title{
Transient elastography (Fibroscan) in HIV-I vertically infected children. A cross-sectional study
}

\author{
Fabrice Monpoux*1, Emilie Huguon ${ }^{1}$, Régine Truchi ${ }^{2}$, Amandine Rubio', \\ Valérie Riolo ${ }^{1}$, Anne Deville ${ }^{1}$, Patrick Boutte ${ }^{1}$ and Albert Tran ${ }^{2}$
}

Address: ${ }^{1}$ Hôpital de l'Archet II - Pédiatrie, Nice, France and ${ }^{2}$ Hôpital de l'Archet II - Clinique des maladies du foie, Nice, France

* Corresponding author

from Fifth Dominique Dormont International Conference. Mother-to-child transmitted viral diseases: from transmission to children care Paris, France. 26-28 March 2009

Published: 22 July 2009

Retrovirology 2009, 6(Suppl I):PI3 doi:10.II86/I742-4690-6-SI-PI3

This abstract is available from: http://www.retrovirology.com/content/6/SI/PI3

(C) 2009 Monpoux et al; licensee BioMed Central Ltd.

Progressive liver toxicity is a concern in HIV-infected patients. Although liver biopsy remains the gold standard for liver assessment, its invasiveness, sampling errors, variability in interpretation and expense do not make it an ideal routine follow-up exam. During the last decade, new non-invasive tools have been developed for the assessment of hepatic fibrosis in HCV and HIV/HCV co-infected patients.

The aim of this cross-sectional study was to evaluate the feasibility of transient elastography (TE) measuring liver stiffness in chronically HIV-infected children. Inclusion criteria were: materno-foetal transmission, age 8 to 18 years old, informed parental consent and patient assent. Twenty-one HIV-1 chronically infected children were included. There were 11 girls and 10 boys, with a median age of 13.2 years (8.3-17.3). Five were HIV stage N, 3 were stage A, 6 were stage B and 6 suffered from AIDS definition illness (stage C). For one orphan child HIV CDC status could not be determined. Mean weight was $46.7 \mathrm{~kg}$ (18.4-83.5), mean height was $151.2 \mathrm{~cm}$ (116-175). Mean CD4 T-cell count at inclusion was 669 cells/mm3 $(256-1,252)$ or $29.9 \%(9.4-45 \%)$, mean viral load was $3.88 \log 10$ copies/mm3 (1.60-4.83). Eight children had undetectable viral load $\left(<40\right.$ copies $\left./ \mathrm{mm}^{3}\right)$. At the time of enrolment, 10 patients received conventional HAART with two NRTIs (nucleoside reverse transcriptase inhibitor) and 1 PI (protease inhibitor), 4 received 2 NRTIs +1 NNRTI (non-nucleoside reverse transcriptase inhibitor), 2 patients were on dual NRTI association, 1 was on triple
NRTI combination and 1 were receiving 1 drug of each class (NRTI+NNRTI+PI). Three children were on planned treatment interruption.

All patients underwent a Fibroscan exam. The two youngest children failed in having a TE measure because of technical difficulties due to their small corpulence. The average measurement success rate was 96.7\%. HIVinfected patients had significantly higher TE results than matched healthy control children $(5.92+/-1.60$ versus $4.34+/-1.10 \mathrm{kPa})(\mathrm{p}<0.02)$. Furthermore, loss of elasticity assessed by TE measures tended to increase with age in a linear manner (adjusted R2: 0.208, p < 0.03). This correlation was found only in the HIV-infected group. We therefore hypothesized that HIV infection and/or continuous exposure to antiretroviral treatment were responsible for this relation.

Our results showed that 1 - evaluation of liver stiffness is feasible in most HIV-1 chronically infected children. 2 Patients had significantly higher TE results than matched healthy control children 3 - the loss of elasticity tended to increase with age in a linear manner. Liver injury should be monitored on a regular basis. The place of TE in the management of these children must be further defined. 